\title{
PERCEPÇÃO AMBIENTAL DE MORADORES DO BAIRRO NOVA PARNAMIRIM EM PARNAMIRIM/RN A SOBRE SANEAMENTO BÁSICO
}

\author{
M. C. B. CUNHA ${ }^{1 *}$ e B. CANNAN ${ }^{2}$ \\ ${ }^{1}$ CAERN/UNP \\ ${ }^{2}$ SENAI DR/RN - Núcleo de Meio Ambiente/UNP \\ candidacunha84@gmail.com*
}

Artigo submetido em setembro/2014 e aceito em fevereiro/2015

DOI: $10.15628 /$ holos.2015.2253

\section{RESUMO}

Saneamento básico é um conjunto de serviços e obras de fundamental importância para a saúde pública, para a qualidade de vida de uma população e para a preservação do meio ambiente. No Brasil, especialmente nas Regiões Norte e Nordeste ainda existem inúmeros problemas a serem superados frente a essa necessidade tão iminente no processo de urbanização e desenvolvimento de um local. O bairro de Nova Parnamirim em Parnamirim/RN se destacou nos últimos 20 anos pelo acelerado crescimento populacional, urbanístico e de infraestrutura, porém, enfrenta graves problemas relacionados ao saneamento básico, especialmente esgotamento sanitário e drenagem urbana.

PALAVRAS-CHAVE: Esgotamento Sanitário. Abastecimento de Água. Drenagem Urbana, Resíduos Sólidos.

\section{ENVIRONMENTAL PERCEPTION OF NEIGHBORHOOD RESIDENTS IN NOVA PARNAMIRIM (PARNAMIRIM/RN) ABOUT SANITATION}

\author{
ABSTRACT \\ Sanitation is a set of services and works of fundamental \\ importance to public health, the quality of life of a \\ population and the preservation of the environment. In \\ Brazil, especially in the North and Northeast still have \\ many problems to be overcome meet this need so \\ imminent in the urbanization and development of a
}

local process. The Nova Parnamirim neighborhood in Parnamirim / RN stood out in the last 20 years by rapid population growth, urbanization and infrastructure, however, faces serious problems related to basic sanitation, especially sanitation and urban drainage.

KEYWORDS: Sanitation. Water Supply. Urbain Drainage. Solid Waste. 


\section{APRESENTAÇÃO}

Saneamento básico, se levarmos em consideração o sentido real da palavra, deve ser algo inicial, de primeira ordem, em qualquer processo de desenvolvimento de uma localidade. Ou seja, é um serviço tão essencial que diversos outros serviços não poderiam existir sem a sua implantação. Porém essa não é a realidade encontrada no Brasil.

Segundo o Sistema Nacional de Informações sobre Saneamento Básico (SNIS) em seu último estudo divulgado no ano de 2011 com base nos dados da Pesquisa Nacional Sobre Saneamento Básico realizada pelo IBGE em 2008, o número de municípios com serviços de abastecimento de água por rede geral de distribuição é de 5.531, o que corresponde a 99,4\% do total de municípios brasileiros. Já o número de municípios que possuem serviço de esgotamento sanitário por rede coletora é de 3.069, o que corresponde a apenas $55,2 \%$ do total de 5.564 municípios do Brasil (IBGE, 2011).

Além de distribuição de água e esgotamento sanitário, o saneamento prever o manejo das águas pluviais e dos resíduos sólidos. Estes serviços também foram verificados e apresentaram os seguintes resultados: 5.256 municípios declararam possuir manejo de águas pluviais, sendo que $94,4 \%$ possuem pavimentação de ruas; a forma de disposição dessas águas também foi verificada, onde $74,4 \%$ utilizam rios permanentes como corpo receptor, $16,9 \%$ utiliza rios intermitentes, $29,0 \%$ lançam ao mar, $10 \%$ em lagoas e $20,7 \%$ em áreas livres públicas ou particulares (IBGE, 2011).

Quanto ao manejo de resíduos sólidos, $100 \%$ dos municípios brasileiros apresentaram esse serviço, porém a destinação final adequada é o grande problema verificado, já que $50,8 \%$ dos municípios ainda utilizam lixões como forma de destinação final; $22,5 \%$ utilizam os aterros controlados e $27,7 \%$ utilizam o aterro sanitário (IBGE, 2011).

Os sistemas de abastecimento de água são caracterizados pela captação da água na natureza em mananciais subterrâneos ou superficiais; adequação de sua qualidade ao padrão de potabilidade vigente por meio de processos físicos, químicos, mecânicos e biológicos de tratamento; transporte até os aglomerados humanos; e fornecimento à população em quantidade compatível com suas necessidades.

Esses sistemas geralmente disponibilizam a água por meio de uma rede geral de distribuição ou, em alguns casos, por meio de sistemas isolados e/ou alternativos, como caso das cisternas.

Atualmente, grande parte dos municípios brasileiros atingiu a universalização desse serviço básico (IBGE, 2011).

Os sistemas de esgotamento sanitário correspondem à implantação da coleta, através de tubulações e galerias; tratamento e posterior lançamento dentro dos padrões adequados em um corpo receptor que pode ser um rio, lago, mar, etc.

Os esgotos podem ser do tipo comercial, industrial e doméstico, e dependendo de suas origens serão caracterizados e receberão o tratamento e a destinação final de acordos com as legislações vigentes. 
Os tipos de destinação final empregado e que são classificados como soluções alternativas no Brasil são as fossas sépticas, empregadas em 1.513 municípios, fossas rudimentares, utilizadas em 947 municípios, fossas secas em 59 municípios, valas a céu aberto em 29 municípios e lançamento em corpos d'água em 34 municípios (IBGE, 2011).

O manejo de águas pluviais refere-se ao controle do escoamento das águas de chuvas para evitar os efeitos adversos que podem representar prejuízos à saúde, segurança e ao bemestar da sociedade.

Os sistemas de drenagem urbana correspondem à pavimentação de ruas, implantação de redes superficiais e subterrâneas de coleta de águas pluviais e destinação final dos efluentes, que se não forem gerenciadas de forma adequada e consciente podem causar diversos problemas como alagamentos, inundações, processos erosivos e de assoreamento.

Obras bem estruturadas, planejadas e projetadas juntamente com a conscientização da população de não jogar lixo ou fazer ligações clandestinas de esgotos nas galerias de água pluvial é o que garante o bom funcionamento dos sistemas de drenagem urbana.

O manejo dos resíduos sólidos compreende a coleta, limpeza pública e destinação final dos resíduos sólidos.

Esses serviços geralmente são realizados por Prefeituras e contam com diversos atores, como cooperativas de coleta seletiva e de catadores, como também com a participação da população e Empresas no correto gerenciamento dos resíduos.

A destinação final adequada depende do tipo de resíduo, que podem ser do tipo comercial, industrial, doméstico, de saúde, varrição e podas, etc. E também se o mesmo poderá ou não ser reciclado e/ou reaproveitado pelos consumidores, produtores e recicladores.

No Brasil, os locais para destinação final basicamente são vazadouro a céu aberto (lixão), aterro controlado e aterro sanitário.

O objetivo desse artigo é apresentar a percepção ambiental de alguns moradores do bairro de Nova Parnamirim quanto aos serviços de saneamento básico e, a relação que esses serviços apresentam para a saúde e o bem estar da população e do meio ambiente.

\section{REVISÃO BIBLIOGRAFICA}

\subsection{Percepção Ambiental}

Cada indivíduo percebe, reage e responde de forma diferente frente às ações sobre o meio, assim ocorre também com as questões ambientais, uma vez que, toda transformação no meio ambiente afeta direta ou indiretamente a qualidade de vida das populações.

Percepção é uma tomada de consciência do ambiente pelo homem, ou seja, ato de perceber o ambiente em que se está inserido, aprendendo a proteger e a cuidar do mesmo (FAGGIONATO, 2011).

Outros autores publicaram artigos relacionados ao tema, como é o caso dos trabalhos: Diagnóstico da percepção dos moradores dos moradores sobre a arborização urbana na Vila 
estação Colônia - bairro Camobi, Santa Maria/RS (ROPPA et al, 2007) e Percepção ambiental de moradores do bairro Liberdade de Parnamirim/RN (BAY \& SILVA, 2011).

Não obstante, a percepção ambiental vem sendo tratada desde 1973 pela UNESCO como forma de planejamento do ambiente e juntamente com a educação e a gestão ambiental devem despontar como forma de defesa do meio natural, de conscientização e de cobrança para os anseios sociais.

Fernandes (2011) destaca que uma das dificuldades para a proteção dos ambientes naturais está na existência de diferenças nas percepções dos valores e da importância dos mesmos entre os indivíduos de culturas diferentes ou de grupos socioeconômicos que desempenham funções distintas, no plano social, nesses ambientes.

Ou seja, percepção ambiental são reações diferentes de cada indivíduo, levando-se em conta o grau de instrução e formação de valores, frente a um mesmo questionamento.

\subsection{Saneamento Básico}

Algumas definições existentes serão apresentadas a seguir, no entanto, pode-se chegar a um consenso, quando relaciona-se saneamento a qualidade de vida e à saúde da população, além da preservação do meio ambiente. Para H. Coing apud Souza (2002), a definição para saneamento é:

Um conjunto de bens e serviços que existem nas cidades, de uso coletivo, que constituem as condições materiais para o funcionamento da cidade enquanto espaço de produção e de consumo e que são ao mesmo tempo suportes das funções estatais (H. COING apud SOUZA, 2002).

É bastante notória a colocação da questão saneamento como função exclusiva do Estado, isso porque se trata do conjunto de obras e serviços, ou seja, a parte física.

É bastante notória a colocação da questão saneamento como função exclusiva do Estado por se tratar de um conjunto de obras e serviços. Segundo a Organização Mundial da Saúde (OMS), saneamento constitui o controle de todos os fatores do meio físico do homem, que exercem ou podem exercer efeitos deletérios sobre seu estado de bem estar físico, mental ou social.

Outra definição diz que:

É o conjunto de ações entendidas fundamentalmente como de saúde pública, compreendendo o abastecimento de água em quantidade suficiente para assegurar a higiene adequada e o conforto, com qualidade compatível com os padrões de potabilidade; coleta, tratamento e disposição adequada dos esgotos e dos resíduos sólidos; drenagem urbana de águas pluviais e controle ambiental de roedores, insetos, helmintos e outros vetores e reservatórios de doenças. (MORAES, 1993).

Moraes (1993) inseriu o controle de roedores, insetos, helmintos e outros vetores relacionando fortemente saneamento com saúde pública. 
A Fundação Nacional de Saúde (2006) procurou ressaltar a proteção ao meio ambiente como benefício do saneamento, e alertou também para o uso adequado do solo.

Saneamento é o conjunto de ações socioeconômicas que tem por objetivo alcançar salubridade ambiental, por meio de abastecimento de água potável, coleta e disposição sanitária de resíduos sólidos, líquidos e gasosos, promoção da disciplina sanitária de uso do solo; drenagem urbana, controle de doenças transmissíveis e demais serviços e obras especializadas com a finalidade de proteger e melhorar as condições de vida urbana e rural (FUNASA, 2006).

Para o entendimento jurídico o saneamento é definido pela Lei $n^{\circ} 11.455 / 2007$ como o conjunto de serviços, infraestruturas e instalações de abastecimento de água potável, esgotamento sanitário, limpeza urbana e manejo de resíduos sólidos e drenagem e manejo das águas pluviais urbanas (BRASIL, 2007).

\subsection{Parnamirim}

Parnamirim foi criado pela Lei $n^{\circ} 2.325$, de $17 / 12 / 1958$, é a terceira cidade mais populosa do Estado do Rio Grande do Norte.

Segundo dados do IBGE (2010), Parnamirim possui 202.456 habitantes, sendo $100 \%$ desses residentes na área urbana. A densidade demográfica é de $1.638,14$ habitantes $/ \mathrm{Km}^{2}$ e 0 IDH do município é de 0,76.

Geograficamente encontra-se a $5^{\circ} 5456$ de latitude Sul e $35^{\circ} 1546$ de longitude Oeste de Greenwich (Inglaterra), apresentando um clima úmido nas áreas centrais e sub-úmido nas áreas mais próximas ao litoral.

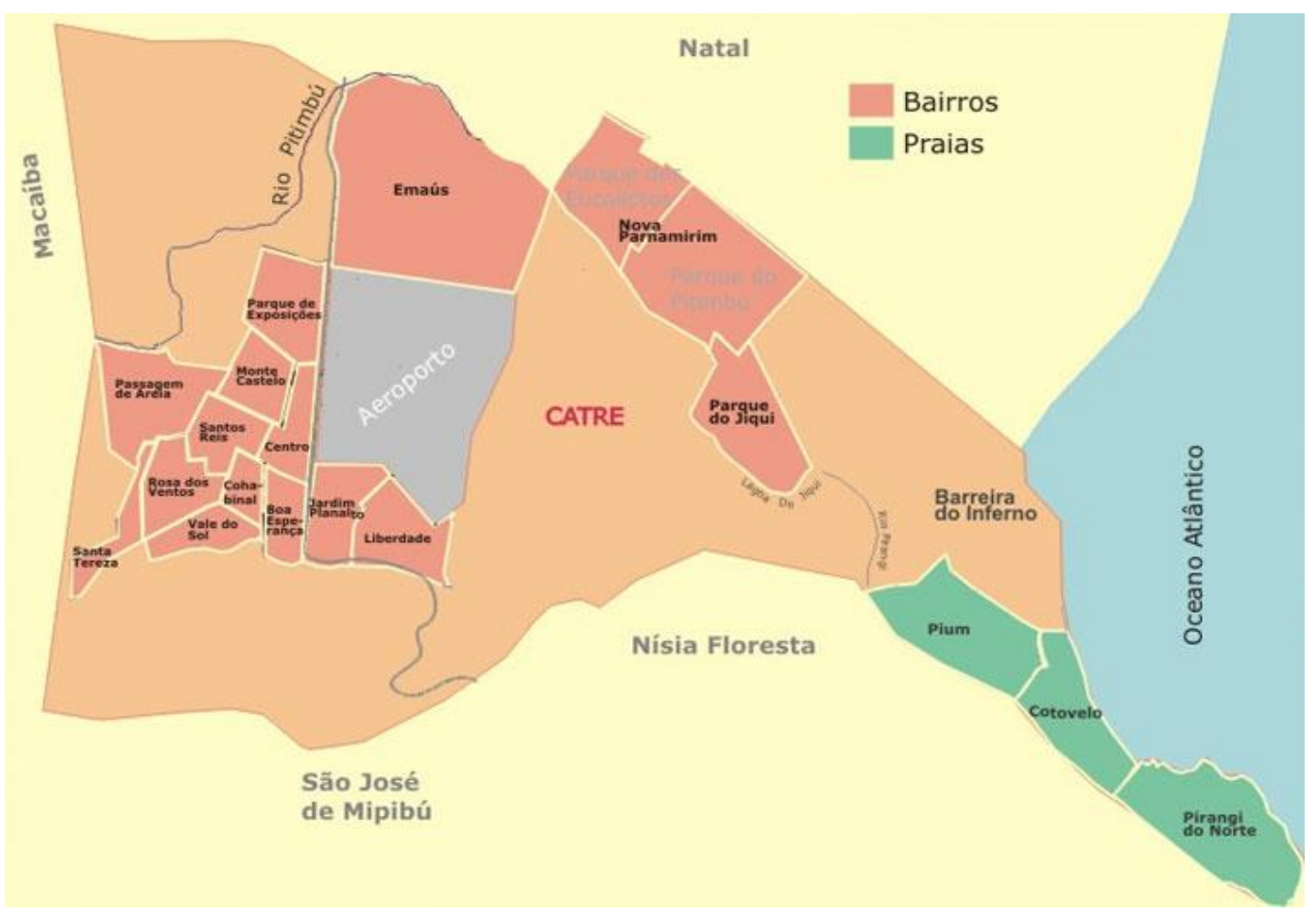

Figura 1 - Mapa dos bairros de Parnamirim/RN. 
O Município de Parnamirim limita-se ao Norte com Natal, ao Sul com os municípios de Nísia Floresta e São José de Mipibú, ao Leste com o Oceano Atlântico e ao Oeste com o município de Macaíba.

A área total é de $123,471 \mathrm{Km}^{2}$, possui 22 bairros e é servido por duas estradas principais, a BR 101 e a BR 304, que ligam o município a o Sul e ao Norte do País.

Na Figura 1 verifica-se os limites geográficos do município, bem como a distribuição dos bairros.

\subsubsection{Saneamento Básico}

O Município de Parnamirim conta com um Plano Diretor baseado na Lei Municipal 1.058/2000 que divide o município em duas zonas: Zona Adensável e Zona de Proteção Ambiental.

A captação de água para abastecimento humano ocorre através de aproximadamente 100 poços tubulares, pertencentes ao Aqüífero Barreiras-Dunas, que apresenta características de excelente qualidade e que até o presente momento supre a demanda do município.

A Companhia de Águas e Esgotos do Rio Grande do Norte (Caern) é a responsável pela captação, tratamento e distribuição das águas e utiliza a desinfecção pela cloração como forma de atender os padrões de potabilidade das águas estabelecidos pela Portaria $n^{\circ}$ 2.914/2011 do Ministério da Saúde.

O sistema de esgotamento sanitário foi dividido em três bacias: Liberdade, Bacia I CentroOeste (demais bairros) e Bacia II Nova Parnamirim (PARNAMIRIM, 2009), atualmente apenas a Bacia Liberdade encontra-se efetivamente em operação, as demais estão em fase de início de obras.

O sistema de drenagem existente no município abrange cinco bacias (Nova Parnamirim, Parque Industrial, Parque de Exposições, Vale do Sol e Liberdade), correspondendo a uma área de aproximadamente $18 \mathrm{~km}^{2}$. O município está dividido em quatro sistemas de drenagem e possui oito lagoas de captação e um complexo de drenagem. A Secretaria Municipal de Limpeza Urbana (SELIM) desenvolve as atividades relativas à manutenção e operação do sistema de drenagem existente (PARNAMIRIM, 2009).

O município possui um plano diretor de resíduos sólidos, elaborado em 2007, quando foi realizado um diagnóstico da situação dos resíduos sólidos do município, no momento foram elaborados mapas georreferenciados das áreas de disposição, planos de serviços e cenário para disposição final, seleção de áreas para disposição dos resíduos e planos de educação sanitária e ambiental (PARNAMIRIM, 2009).

Os serviços de limpeza urbana do município são gerenciados pela Secretaria Municipal de Limpeza Urbana (SELIM) e compreendem os seguintes itens abaixo descritos: Coleta Domiciliar; Coleta de Resíduos de Saúde; Coleta de Poda; Coleta de Entulho (Lixo Diversificado); Coleta de Resíduos de Construção; Varrição, Capinação e Pintura de Meio Fio; Catação; Serviço de Podação; etc (PARNAMIRIM, 2009).

O destino final dos resíduos domiciliares coletados em Parnamirim é o Aterro Sanitário Metropolitano, os outros tipos de resíduos são depositados numa área particular conhecida 
como Lixão da Liberdade para Podas e Entulhos localizados no bairro da Liberdade (PARNAMIRIM, 2009).

\subsubsection{Nova Parnamirim}

Nova Parnamirim é considerado o mais próspero e populoso bairro de Parnamirim, segundo dados do IBGE no ano de 2010 o bairro possuía 54.076 habitantes. E nos últimos vinte anos apresentou um crescimento em torno de $195 \%$.

Nova Parnamirim concentra boa parte da classe média emergente da região metropolitana do Natal, recebendo ano após ano um grande número de novos moradores, atraídos pelo preço relativamente acessível dos imóveis e também por toda a infraestrutura apresentada no bairro.

O bairro é um misto de residencial e comercial, onde diversas redes de supermercados, farmácias e lanchonetes se instalaram para que a demanda crescente dos consumidores não precisassem mais ir até a Natal para atender suas necessidades.

No entanto, todo esse crescimento acelerado, populacional e urbanístico, veio de forma rápida e sem o planejamento adequado. Pois, apesar do bairro possui os serviços abastecimento de água, drenagem urbana e coleta de resíduos sólidos, estes acabaram por sofrer interferências da falta de um item que é o esgotamento sanitário.

\section{METODOLOGIA}

Foram realizadas cerca de 40 entrevistas com moradores do bairro entre os dias 21 e 22 de julho de 2014. Onde foi aplicado um questionário com perguntas relativas ao saneamento básico, grau de satisfação com os serviços de saneamento existentes no bairro, possíveis reclamações existentes, qualidade e racionamento de água e também se verificou o perfil dos entrevistados.

\section{RESULTADOS E DISCUSSÕES}

A grande maioria dos entrevistados relaciona saneamento básico a existência apenas de esgotamento sanitário; uma pequena parcela reconhece a existência de outros elementos como a distribuição de água potável e/ou a coleta de resíduos sólidos (lixo), porém a minoria consegue perceber as quatro vertentes do saneamento na concepção geral do tema.

O primeiro questionamento referiu-se a percepção que cada morador tem ou entende sobre saneamento básico. As respostas variaram bastante, porém a maioria dos entrevistados atrelaram saneamento básico a rede de esgoto e coleta de lixo, como citado anteriormente, poucas vezes se utilizou a palavra drenagem urbana na definição.

Apesar de muitos moradores compreenderem a importância do saneamento para a proteção dos mananciais, do meio ambiente e especialmente para a melhoria da saúde e da qualidade de vida da população é perceptível também a relação entre saneamento e a limpeza das ruas, sobretudo se essas estiverem sem esgotos correndo nas sarjetas. 
Outra percepção bem notória é a conscientização de que cada um é responsável pela preservação e conservação dos recursos, principalmente quando questionados sobre sua relação com o desperdício de água, grande parte dos entrevistados admitiram economizar água, frente a importância desse bem natural.

Alguns entrevistados também enfatizaram que os serviços de saneamento básico são e devem ser oferecidos pelos Poderes Públicos de forma gratuita e continuar.

Segue abaixo exemplos de respostas obtidas nas entrevistas no item 0 que você entende por saneamento básico:

"São medidas tomadas pela administração pública para o bem-estar da população contemplando coleta e distribuição de água potável, manejo de águas pluviais, coleta e tratamento de esgotos e lixo, e controle de pragas e insetos vetores de doenças."

"Saneamento básico consiste nas ações ambientais que fornecem o atendimento às necessidades básicas de saúde tais como abastecimento de água, esgotamento sanitário, drenagem urbana e coleta de resíduos sólidos."

"Coleta de resíduos (esgotos domésticos e industriais) para evitar a contaminação dos mananciais."

"Infraestrutura que o município oferece aos seus moradores para drenar águas pluviais e águas de uso geral."

"Fossa e esgoto"

É interessante lembrar que o nível de escolaridade dos entrevistados variou, porém, o próprio bairro se destaca pela presença de moradores das classes média e alta. O que de certa forma, contribui para um nível de esclarecimento maior por parte dos entrevistados.

Outra questão verificada foi a importância do saneamento básico para a população; boa parte dos moradores enfatizaram ser muito importante para melhoria da qualidade de vida, sobretudo, para a saúde da população.

Diversas vezes foram citadas a importância do saneamento para evitar a contaminação do lençol freático, propagação de doenças e para proteção dos mananciais.

Quando questionados sobre a satisfação dos serviços de saneamento existentes no bairro, o grau de satisfação variou de acordo com cada serviço prestado.

Quanto à água distribuída cerca de $70 \%$ dos entrevistados declararam está satisfeitos com a qualidade e quantidade de água fornecida. Os 30\% restantes declararam está insatisfeitos devido a desconfiança sobre qualidade da água, alguns chegaram a reclamar do residual de cloro presente na água, sem saber da importância desse tipo de tratamento (desinfecção) que elimina a proliferação de microrganismos patógenos nas águas. Além, também, da insatisfação quanto a irregularidade do fornecimento de água em algumas ruas do bairro (intermitência).

Novamente algumas das afirmações obtidas pelos moradores do bairro de Nova Parnamirim quanto ao serviço de distribuição de água: 
"A água de Parnamirim tem um que de água mineral."

"Com a oferta sim, mas a qualidade. Acho que ainda pode melhorar."

"Sim. Mas às vezes falta água."

Quando questionados sobre o esgotamento sanitário a maioria dos moradores está insatisfeita com esse serviço. O alto grau de insatisfação é, sobretudo, pelo de que no bairro não existe rede de esgotamento sanitário. Uma minoria declarou está satisfeita com os serviços de esgotamento sanitário, alguns por não compreenderem o grande risco que a falta de um sistema adequado para captação dos efluentes domésticos pode causar ao meio ambiente e a saúde pública e em outros casos por interpretarem que fossa sépticas e/ou sumidouros sejam suficientes para atenderem suas necessidades.

Todavia, a maioria dos entrevistados percebe que o uso de fossas e sumidouros está diretamente ligada a contaminação das águas e do meio ambiente.

Abaixo algumas respostas obtidas sobre a percepção dos moradores quanto a importância do esgotamento sanitário:

"Não. Muita água a céu aberto."

"Não. Até onde sei em minha casa em Nova Parnamirim a forma de esgotamento ocorre através do Sistema de fossa-sumidouro, não existindo um serviço público unificado de tratamento de esgoto."

"Precisa sanear. Já que pagamos IPTU tão caro."

Os serviços de drenagem urbana também foram pesquisados, e a percepção quanto a esse serviço tão importante para o controle de pragas, insetos e também para a conservação de vias e mananciais, são bastante aquém para a maioria dos entrevistados, já que muitos não atribuem esse serviço como parte do pacote saneamento básico.

A maioria dos moradores entrevistados apontou como problemas de drenagem a existência de pontos de alagamento no bairro. E, atrelaram drenagem urbana apenas a lagoas de captação e demais equipamentos de drenagem das águas de chuva, como bocas de lobo e galerias. Poucos citaram a pavimentação de ruas.

No entanto a grande insatisfação percebida é com os alagamentos em alguns pontos do bairro e essa questão foi bastante repetida, assim como a presença de insetos devido a esses pontos de alagamentos.

Quanto ao grau de satisfação com esses serviços, segue abaixo algumas respostas obtidas que representam em sua maioria a percepção dos entrevistados:

"Torna viável o escoamento das águas de chuva sem causar alagamentos e transtornos à população."

“Não. Há muitos alagamentos."

"Sim. Não temos problemas de alagamentos." 
Quanto aos serviços de coleta dos resíduos sólidos foi verificado que a maioria dos moradores está satisfeita, porém, alguns reclamam da demora da coleta, que era para ocorrer três vezes por semana.

Como o bairro possui coleta de resíduos sólidos permanente, grande parte dos moradores entrevistados não conseguiram perceber esse serviço como parte do saneamento básico, sobretudo, frente a questão rotineira que esse serviço é ofertado a população.

A grande reclamação ficou para a demora da coleta, em alguns casos, e pela falta de uma política de incentivo a coleta seletiva que não existe no bairro. Tanto que a maioria dos entrevistados quando perguntados sobre se faziam a separação do lixo responderam que sim, porém desconhecem a destinação que os catadores e/ou empresa de coleta de resíduos sólidos da ao seu lixo.

Abaixo algumas afirmações sobre o serviço de coleta dos resíduos sólidos apresentados pelos entrevistados:

\footnotetext{
"O que tenho a reclamar sobre a coleta de resíduos sólidos no meu bairro é o não cumprimento da data de coleta semanal."

“Não. Demora muito a passa."

"Sim. A coleta ocorre toda segunda, quarta e sexta-feira."
}

\section{CONCLUSÃO}

Conclui-se então que os moradores do bairro Nova Parnamirim em sua maioria estão satisfeitos com o sistema de distribuição da água, porém alguns estão preocupados com sua qualidade quando reclamam do teor de cloro residual presente na água, sem entender a importância desse composto para o controle de contaminações na rede de distribuição de abastecimento de água.

No quesito esgotamento sanitário, como o bairro não possui sistema de coleta, tratamento e destinação final dos efluentes domésticos, é quase unânime a insatisfação com a falta desse serviço essencial para a proteção da saúde pública e do meio ambiente. Os moradores que se declararam satisfeitos devem desconhecer tal fato.

A drenagem urbana no bairro existe, as ruas são calçadas ou asfaltadas, existem galerias de água pluvial e lagoas de captação em alguns pontos do bairro. No entanto, devido ao descarte de ligações clandestinas de esgotos, e descarte irregular de resíduos sólidos essas galerias e demais sistemas ficam sobrecarregados gerando problemas sérios de alagamentos nas áreas mais baixas do bairro. Sendo essa a principal reclamação e insatisfação por parte dos moradores.

A coleta de resíduos sólidos ocorre três vezes por semana, porém muitos moradores reclamaram da demora dessa coleta que deveria ser mais frequente e da falta de políticas públicas para incentivar a coleta seletiva, através de campanhas educativas. Porém, no geral a população está satisfeita com esse serviço.

A principal reclamação é quanto à contaminação do manancial de abastecimento de água da região que são os poços tubulares, sobrecarga nas galerias de águas pluviais devido à 
existência de ligações clandestinas de esgotos e também, pelo lançamento irregular de efluentes nas ruas causando maus odores e proliferação de insetos.

O grande desafio é a implantação de um sistema de esgotamento sanitário, pois, a falta desse item afeta direta e indiretamente a qualidade de vida dos moradores.

Conclui-se então que a percepção ambiental quanto ao tema saneamento básico é variável, algumas vezes discordante e sempre única e distinta. Os problemas existem, porém são percebidos de forma variada e/ou até relacionados às diferentes fatores.

\section{REFERÊNCIAS BIBLIOGRÁFICA}

1. BAY, A. M. C. \& SILVA, V. P. da;. Percepção Ambiental de Moradores do Bairro de Liberdade de Parnamirim/RN sobre a Implantação do Esgotamento Sanitário. Revista HOLOS. Natal. v.3, p.97-112, 2011.

2. BRASIL. Lei $n^{\circ} 11.445$, de 05 de Janeiro de 2007.

3. BRASIL. Portaria $n^{\circ} 2.914$, de 12 de Dezembro de 2011.

4. FAgGIONATO, Sandra. Percepção ambiental. Materiais e Textos, 2011. Disponível em: http://educar.sc.usp.br/biologia/textos/m_a_txt4.html. Acesso em: 24 jun. 2014.

5. FERNANDES, Roosevelt. S. et al. Uso da Percepção Ambiental como Instrumento de Gestão em Aplicações ligadas às Áreas Educacional, Social e Ambiental. Disponível em: < http://www.anppas.org.br/encontro_anual/encontro2/GT/GT10/roosevelt_fernandes.pdf>. Acesso em: 20 jun. 2014.

6. FUNDAÇÃO NACIONAL DE SAÚDE (FUNASA). Manual de saneamento. 4ạ ed. Brasília: Fundação Nacional de Saúde, 2006.

7. Instituto Brasileiro de Geografia e Estatística (IBGE). Atlas do Saneamento 2011. Disponível em: <http://www.ibge.gov.br/estatistica/populacao/atlas/defaul_saneamento.sthm>. Acesso em: 24 jun. 2014.

8. Instituto Brasileiro de Geografia e Estatística (IBGE). Censo 2010. Disponível em: < http://www.cidades.ibge.gov.br/xtras/perfil.php?lang=\&codmun=240325\&search=riogrande-do-norte|parnamirim>. Acesso em: 20 jun. 2014.

9. MORAES, Luiz Roberto S. Conceitos de Saúde e Saneamento. Salvador: DHS/UFBA, 1993. 6p. Não Publicado.

10. PREFEITURA DE PARNAMIRIM. Plano Municipal de Saneamento Ambiental de Parnamirim: Diagnóstico Social e Setorial - Etapa II. Parnamirim, 2009.

11. ROPPA, Cristiane et al. Diagnóstico da Percepção dos moradores sobre a Arborização Urbana na Vila Estação Colônia - Bairro Camobi, Santa Maria - RS. Revista da Sociedade Brasileira de Arborização Urbana, v.2, n.2, 2007. Disponível em: <http:// http://www.revsbau.esalq.usp.br/artigos_cientificos/artigo18.pdf>. Acesso em 20 jun. 2014.

12. SOUZA, Maria Salete de. Meio Ambiente e Saneamento Básico. Mercator - Revista de Geografia da UFC. Ano 01, Número 01, 2002. Disponível em: <http://www.mercator.ufc.br/index.php/mercator/article/viewFile/194/160>. Acesso em: 20 jun. 2014. 